\title{
CHALCONE DYEING ON SILK FABRICS PRETREATED WITH CHITOSAN: OPTIMIZATION, ISOTHERM AND KINETICS
}

\author{
Riskiono Slamet
}

Jurusan Kimia Fakultas MIPA Universitas Negeri Jakarta Jl. Pemuda No 10, Rawamangun 13220, Jakarta, Indonesia

Email : riskiono_slamet@Yahoo.com

\begin{abstract}
Surface response methodology was involved in the optimization of chalcone adsorption upon silk fabrics treated with chitosan against the process parameters $\mathrm{pH}$, temperature and contact time. The effects of these factors were studied in the ranges 4.0-6.0, 85-95 $\mathrm{C}$ and 20-60 min at initial concentration chalcone dye 500 $\mathrm{mg} . \mathrm{L}^{-1}$, respectively. A predictive quadratic model was constructed by variance analysis of data obtained from a total of 20 experimental runs with three replicates each. The maximum q $279 \mathrm{mg} / \mathrm{g}$ was found under the experimental conditions of $\mathrm{pH}=5.0$, contact time $=40$ and temperature $=90$. Out of Langmuir isotherm models, adsorption data was best described by Langmuir isotherm with 0.99 consistency. The process kinetics was evaluated by pseudo-second order. Pseudo-second order kinetic model exhibited the highest correlation with data. The results showed that both monolayer adsorption and intra-particle diffusion mechanisms limited the rate of chalcone adsorption.
\end{abstract}

Keywords:Chalcone, silk fabrics, optimization, kinetics and isotherm

\section{Introduction}

Manufacturing of synthetic dyes largely depends on petrochemical sources and many of these are toxic, resulting in environment pollution[1]. Natural dyes comprise colorantsthat are obtained from animal or vegetable substances without any chemical processing. This group is mostly known to be eco-friendly, biodegradable, low toxic, and less allergenic as compared to synthetic dyes [2] Besides, it can have a higher compatibility with the environment. For these raisons, considerable research work is beingundertaken around the world about the production and applicationof natural dyes [3]

Chalcones are well known as natural dyes. Chemically, they presents open chain analogues of flavonoids in which two aromatic rings are joined by three carbons, $\alpha, \beta$ unsaturated system[4] (Fig. 1) such as saffron, these chromophores absorb light at longer wavelengths and have more golden/orange hues. They are precursors in flavonoids biosynthesis and play an ecological role in nature, in relation to plants colour.Historically, chalcone dyes were used by people for colouring textile materials. They have been recently identified in ancient Andean textile, as marein and other glucisides of okanini $\left(2^{\prime}, 3^{\prime}, 4^{\prime}\right)$-pentahidroksichalcone)-

pentahydroxychalcone), possibly obtained from a Coreopsis species (Fig. 2) [5]

Recently, many statistical experimental design methods havebeen developed for process optimization [4]. Among them, response surface methodology stands out as a popular method utilized in many fields [6-7]. Many researches have been published in the literature on the on the RSM effect of optimization processing [8-9].Therefore, the use of response surface methodology was introduced in this experimental research.

\section{Materials and methods}

\subsection{Materials}

Silk fabrics were obtain from Rumah Sutera Alam, Ciapus, Bogor, West Java, Indonesia and chitosan purchased from Laboratory Badan Tenaga Atom Nasional, Jakarta. Fresh chalconeoid dyes was purchased from Laboratory Biology State university of JakartaA. cyanophylla was 
collected in the region of Depok, West Java in March 2011. The plant was identified in Laboratory of Plant Biology and Botany State University of Jakarta

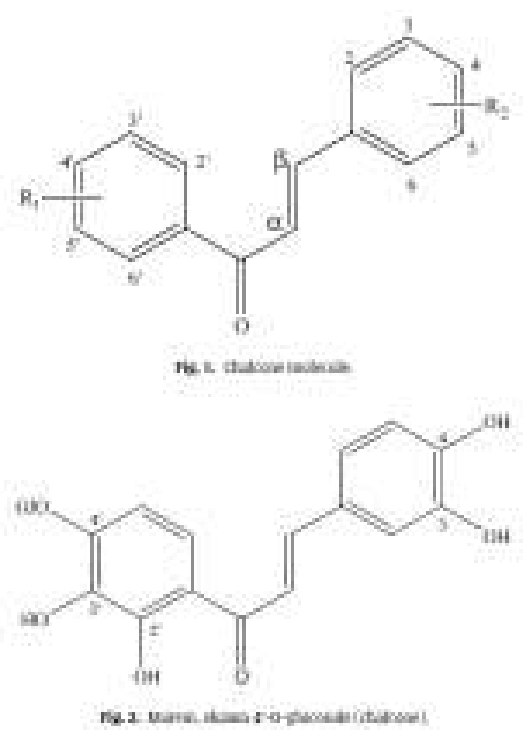

\subsection{Coating silk fabri}

Silk degumming was performed using raw silk fabricwere treated with $1.5 \mathrm{~g} / \mathrm{L}$ Marseille soap, $0.5 \mathrm{~g} / \mathrm{L}$ sodium carbonate,and silvatol (anionic surfactant) at $70-75^{\circ} \mathrm{C}$ for $15 \mathrm{~min}$ and dried.Degummed silk fibers were coating with chitosan solutions of concentrations $1.5 \%$ $(\mathrm{w} / \mathrm{v})$ in $2.0 \%(\mathrm{v} / \mathrm{v})$ aqueous acetic acid The silk fabrics were than immersed in chitosan solutions for $24 \mathrm{~h}$ at room temperature. The fabrics were then padded and cured in the curing chamber at $120^{\circ} \mathrm{C}$ for $5 \mathrm{~min}$.

Table 1 Independent variable values of the process and their corresponding levels.

\begin{tabular}{|l|l|l|l|l|}
\hline No & Variable & \multicolumn{3}{|c|}{ Variables levels } \\
\hline 1 & pH chalcone & 4.0 & 5.0 & 6.0 \\
\hline 2 & Contact time $(\mathrm{min})$ & 30 & 60 & 90 \\
\hline 3 & Temperature $\left({ }^{0} \mathrm{C}\right)$ & 90 & 95 & 100 \\
\hline
\end{tabular}

\subsection{Chalcone dye extraction from A.} cyanophylla

The dried and powdered flowers $(1 \mathrm{~kg})$ of A. cyanophylla were extracted with methanol at room temperature for $48 \mathrm{~h}$. The correspondingextract was obtained after
Table 2. Central composite design arrangement and results.

\begin{tabular}{|c|c|c|c|c|}
\hline No & $\mathrm{pH}$ & $\begin{array}{c}\text { Time } \\
(\mathrm{min})\end{array}$ & $\begin{array}{c}\text { Tempe } \\
\text { rature } \mathrm{C}^{\mathrm{C}}\end{array}$ & $\begin{array}{c}\text { adsorption } \\
\text { capacity } \\
(\mathrm{mg} / \mathrm{g})\end{array}$ \\
\hline 1 & 4.00 & 30.00 & 90.00 & 88.47 \\
\hline 2 & 6.68 & 60.00 & 95.00 & 78.42 \\
\hline 3 & 4.00 & 90.00 & 95.00 & 93.12 \\
\hline 4 & 5.00 & 60.00 & 90.00 & 76.89 \\
\hline 5 & 5.00 & 90.00 & 90.00 & 93.36 \\
\hline 6 & 5.00 & 60.00 & 100.00 & 89 \\
\hline 7 & 5.00 & 60.00 & 95.00 & 84.71 \\
\hline 8 & 4.00 & 65.00 & 95.00 & 59.99 \\
\hline 9 & 5.00 & 60.00 & 90.00 & 85.52 \\
\hline 10 & 4.00 & 30.00 & 90.00 & 72.38 \\
\hline 11 & 4.00 & 30.00 & 95.00 & 84.98 \\
\hline 12 & 6.00 & 60.00 & 95.00 & 64.42 \\
\hline 13 & 5.00 & 30.00 & 90.00 & 96.07 \\
\hline 14 & 5.32 & 60.00 & 90.00 & 80.69 \\
\hline 15 & 5.00 & 60.00 & 90.00 & 59.77 \\
\hline 16 & 5.00 & 60.00 & 90.00 & 92.81 \\
\hline 17 & 4.00 & 60.00 & 95.00 & 96.56 \\
\hline 18 & 5.00 & 30.00 & 100.00 & 82.84 \\
\hline 19 & 5.00 & 30.00 & 90.00 & 64.11 \\
\hline 20 & 4.00 & 30.00 & 90.00 & 82.03 \\
\hline & & & & \\
\hline
\end{tabular}

filtration and evaporation of the solvent under reduced pressure. The obtained methanolicextract $(10 \mathrm{~g})$ was dissolved in water then extracted successivelywith $\mathrm{CHCl}_{3}$ and ethyl acetate to yield the corresponding extracts. The ethyl acetate extract $(5 \mathrm{~g})$ was subjected to silica gel column chromatography eluting with $\mathrm{CHCl}_{3} / \mathrm{MeOH}$ gradients. Sixmain fractions $(250 \mathrm{~mL} \times 6)$ were collected. After evaporation of thesolvent in vaccuo, fraction 5 (4 g) was purified by column chromatography over silica gel using $\mathrm{CHCl}_{3} / \mathrm{MeOH}$ (8:2) as eluent toafford 1 (3.5 g). The extraction yield of compound 1 is $0.72 \%$.

\subsection{Dyeing procedure}

The silk fabrics was treated with a solution containing $5.0 \mathrm{~g} \mathrm{~L} \mathrm{~L}^{-1}$ non-ionic detergent, at $50^{\circ} \mathrm{C}$ for $30 \mathrm{~min}$. Then the silkfabrics was thoroughly washed with water and air dried at room temperature. Chalcone 


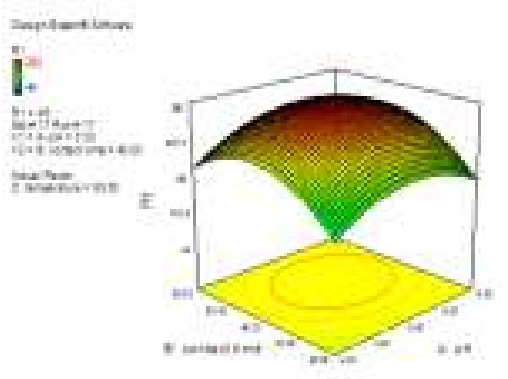

FIGURE 1 The effect of $\mathrm{pH}$ on adsorption capacity

dye was dissolved in water to the required concentrations; hence, Ethanol with absolute percent of 99.0 was used to solve the dye. Dye bath containing $1.0 \mathrm{~g}$ silk fabrics different buffer solutions pHs (3.0-11.0), times (10-120 $\mathrm{min}$ ) and temperatures (40-100 $\left.{ }^{\circ} \mathrm{C}\right)$ were prepared with dye liquor ratio $(40: 1)$. The pri-mary Dye concentration in all dye baths was $5.0 \times 10-4 \mathrm{~mol} \mathrm{L-1}$. These were determined at time zero and at subsequent times using a calibration curve based on absorbance at _max $=458 \mathrm{~nm}$ versus dye concentration in standard rutin dye solutions. The dyed samples were rinsed with cold water, washed in a bath of liquor ratio 40:1 using $3.0 \mathrm{~g} \mathrm{~L}-1$ nonionic detergent at $50 \circ \mathrm{C}$ for $30 \mathrm{~min}$, then rinsed and finally dried at ambient temperature. The percentage of dye bath exhaustion (E\%) was calculated according to the following Eq. (1):

$$
\% E=\frac{\text { Co-Ce }}{\text { Co }}
$$

Where $\mathrm{Co}$ and $\mathrm{Ce}$ are the concentration of dyebath before and after dyeing, respective

\subsection{Design of experiments}

Central composite design was employed in the experimental design procedure. Chalcone dye was dissolved in water to the required concentrations; hence, ethanol with absolute percent of 99.0 was used to solve the dye. Dye bath containing $5 \mathrm{~g}$ silk, prepared with dye liquor ratio (100:1). The primary dye concentration in all dye baths was $0.3 \%$. The amount of dye adsorbed pergram of silk (qt) $(\mathrm{mg} / \mathrm{g}$ silk) at any time was calculated by a mass balance relationship (Eq. 1) as follows:

$$
\begin{array}{ccc}
\mathrm{Ce} & \mathrm{Ce} & 1 \\
-\mathrm{qe} & \mathrm{qm} & \text { qmK }
\end{array}
$$

The effects of process parameters $\mathrm{pH}$, contact time and temperature were investigated at three levels as summarized in Table 1

In case of insignificance the variable was omitted from the predictive model (Eq. 2).

$Y=b_{0}+b_{1} X_{1}+b_{2} X_{2}+b_{3} X_{3}+b_{1} b_{2} X_{1} X_{2}+b_{1} b_{3} X_{1} X_{3}$

$+b_{2} b_{3} x_{2} x_{3}+b_{1} x_{1}^{2}+b_{2} x_{2}^{2}+b_{3} x_{3}^{2}$

where $Y$ is the predicted response, $b_{0}$ the offset term, $X_{1}$ is the $\mathrm{pH}, \mathrm{X}_{2}$ is the contact time, $x_{3}$ is the temperature, and $b_{1}, b_{2}$, and $b_{3}$ are the coefficients of the adjusted equation.

Regression and graphical analysis of the experimental design data and evaluation of the statistical significance of the second order polynomial equations were carried out using Design Expert software (version 7.1.5, STATEASE Inc., Minneapolis, USA). The optimum preparation conditions were estimated through regression analysis and threedimensional response surface plots of the independent variables and each dependent variable.

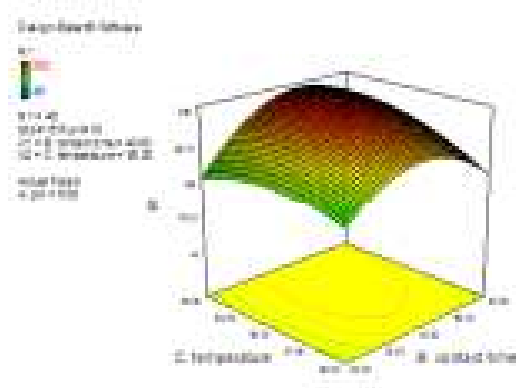

FIGURE 2 Effects of contact time on adsorption capacity 


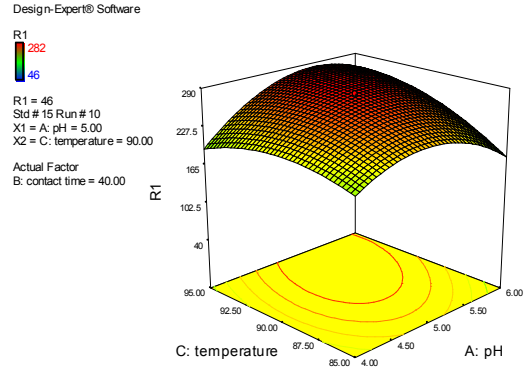

FIGURE 3 Effects of temperature on adsorption capacity

\section{Result and discussion}

Optimizition conditions for Chalcone dyeing of silk fabric

Effects of $\mathrm{pH}$ of chalcone, contact time and temperatur on $\mathrm{q}$ were studied during, experimentation. These parameters were chosen during the preliminary study which gave the highest $\mathrm{q}$. The results of 20 runs using CCD showed that the $q$ ranged from 46 to 279 $\mathrm{mg} / \mathrm{g}$. The maximum q $270 \mathrm{mg} / \mathrm{g}$ was found under the experimental conditions of $\mathrm{pH}=$ 5.0, contact time $=40$ and temperature $=90$ As shown in Table 2, the total numbers of 20 experimental runs based on central composite designs (CCD) with six center points were performed By applying least squares method and multiple regressionand the interaction term $\mathrm{X}_{1}, \mathrm{X}_{2}, \mathrm{X}_{3}$, were significant model terms. It can be revealed that independent variables individually affected dependent variable

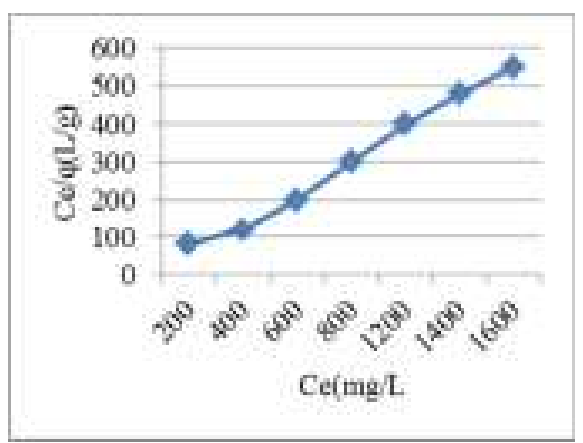

FIGURE 4. Equilibrium isotherm for the adsorption of Chalcone on silk fabric treated with chitosan
By applying least squares method and multiple regression analysis on the experimental results, the following second order polynomial equation was found to explain the dependent variable by considering the significant terms and was shown in Eq. (3).

$Y=83.555+11.78 X_{1}+23.55 X_{2}+11.54 X_{3}+7.3$

$X_{1} X_{2}+14.13 X_{1} X_{3}+29.38 X_{2} X_{3}-3.75 . X_{1}{ }^{2}-$ $63.80 X_{2}^{2}-24.55 X_{3}^{2}$

\section{Model fitting}

The F-value is calculated for each type of model, and the highest order model with significant terms normally would be chosen. The first step sequential F-value tests were performed using analysis of variance (ANOVA). As shown in Table 3, the quadratic model is the highest order model with significant terms, due to the P-value of quadratic model is less than that of other model; therefore, it would be the recommended model for this experiment design. The cubic model was found to be aliased. Typically, regression analyses for different models indicated that the fitted quadratic models accounted for more than $95 \%$ of the variations in the experimental data, which were found to be highly significant. The independent variables were fitted to the recommended quadratic equation and examined for the goodness of fit

\section{Surface and contour plots}

Surface and contour plots were used in determination of the optimum set of process conditions. The surfaces constructed under the combined effect of process parameters are shown in Figs. 1-3

\section{The $\mathrm{pH}$ effect}

The effect of $\mathrm{pH}$ on the adsorption of chalcone dye onto silk at $30^{\circ} \mathrm{C}$ with the initial dye concentration of $500 \mathrm{mg} / \mathrm{L}$ and the MLR of 1:100 is shown in Fig. 1. It indicated that the 
Table 3 Statistical parameters for sequential models.

\begin{tabular}{|l|l|l|l|l|l|}
\hline Source & $\begin{array}{l}\text { Degrees } \\
\text { of freedom }\end{array}$ & $\begin{array}{l}\text { Sum } \\
\text { of squares }\end{array}$ & $\begin{array}{l}\text { Mean } \\
\text { square }\end{array}$ & F-value & P-value \\
\hline Linear & 11 & $1.273 \mathrm{E}+005$ & 11568.81 & 4338.31 & $<0.0001$ \\
\hline $2 \mathrm{FI}$ & 8 & $1.194 \mathrm{E}+005$ & 14930.57 & 5598.97 & $<0.0001$ \\
\hline Quadratic & 5 & $\underline{35013.52}$ & $\underline{7002.70}$ & $\underline{2626.01}$ & $<\underline{0.0001}$ \\
\hline Cubic & 1 & 743.48 & 743.48 & 278.80 & $<0.0001$ \\
\hline Pure error & 5 & 13.33 & 5.33 & & \\
\hline
\end{tabular}

adsorption capacity increased with decreasing $\mathrm{pH}$ over the $\mathrm{pH}$ range 5.0-4.0, The highest adsorption capacity was observed to be in the $\mathrm{pH}$ range of 5.0-4.5. This is due mainly to an increase in the protonation of the amino ($\mathrm{NH} 2$ ) groups of aminoacids in the silk protein, while the carboxyl groups in theside chains are essentially unionized at lower $\mathrm{pH}$.

\section{The effect of contact time}

The adsorption of chalcone dye at different contact time onto silk was investigated as a function of temperature is shown in Fig. 2. It was found that the adsorption capacity was concentration dependent and increased with temperature of the chalcone dye. An increase in the temperature led to an increase in the amount of dye adsorbed onto silk. This may be a result of an increase in the driving force of the contact time gradient with the increase in the temerature. This indicated that the temperature plays an important role in the adsorption capacity of chalcone dye onto silk.

\section{The effect of temperature}

The results of the studies on the influence of temperature on the adsorption of chalcone dye onto silk areshown in Fig. 3. Before and after the equilibrium time, the amount of dye adsorbed per gram of silk (qt) showed different trends at different temperatures. Before the equilibrium time, the initial dye adsorption rate increased with increasing temperature which indicated a kinetically controlle. This result may reflect an increase in the mobility of the large dye ions with temperature and thus an increase increase in the number of molecules interacting with the active sites at the surface.

After the equilibrium. time, the decrease of the amount of the dye adsorbed per gram of silk with increasing temperature indicated that the adsorption of chalcone dye onto silk was controlled by an exothermic process. The equilibrium of the chalcone dyeing process was shifted to the left-hand side. Therefore, the amount of dye adsorbed at high temperature was lower than that at low temperature after the equilibrium time.

\section{Adsorption isotherm}

The equilibrium isotherm for the adsorption of chalcone by the silk fabric at $\mathrm{pH}$ 5.0 and $25^{\circ} \mathrm{C}$ was shown in Fig. 1. The equilibrium data were fitted by Langmuir and Freundlich isotherm equations. The Langmuir equation can be expressed as

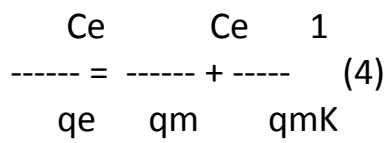

where $q e$ is the adsorption capacity $\left(\mathrm{mg} \mathrm{g}^{-1}\right)$ based on thedry weight of nano-adsorbent, $\mathrm{Ce}$ is the equilibrium concentration (mg.L ${ }^{1}$ ) in solution, $q \mathrm{~m}$ is the maximum adsorption capacity (mg g-1), and $K$ is the Langmuir adsorption equilibrium constant $\left(\mathrm{L} \mathrm{mg}^{-1}\right)$. The values of Langmuir constants $q m$ and $b$ were obtained from the intercept and slope of the plot between $(1 / q e)$ vs. $(1 / \mathrm{Ce})$ presented in Fig. 4. From the slope and intercept in the inset of Fig. 4, the values of qm and $\mathrm{K}$ might be 
Table 3 data kinetic experiment

\begin{tabular}{|l|l|l|l|}
\hline Temperature $\left({ }^{0} \mathrm{C}\right)$ & qe,exp & \multicolumn{2}{|l|}{ Pseudo second-order model } \\
\cline { 3 - 4 } & (mg/g silk) & k2(g silk/mg.min) & $\mathrm{R}^{2}$ \\
\hline 85 & 173 & 0.146 & 0.9990 \\
\hline 90 & 279 & 0.964 & 0.9998 \\
\hline 95 & 260 & 0.085 & 0.9989 \\
\hline
\end{tabular}

estimated as $279 \mathrm{mg} / \mathrm{g}$ and $0.034 \mathrm{l} / \mathrm{mg}$, respectively.

\section{Kinetics of adsorption}

In order to analyze the adsorption kinetics of chalcone dye on silk, the pseudo second order kinetic models Asimple kinetic analysis of adsorption is the Lagergren equation(5).

$$
\begin{array}{ccc}
t & 1 & 1 \\
---- & ----- & +---t \\
q_{t} & k_{2} q_{e}^{2} \quad q_{e}
\end{array}
$$

A straight line of $\left(t / q_{t}\right)$ versus $t$ suggests the applicability of this kinetic model to fit the experimental data. The slopes and intercepts of these plots were used to calculate the adsorption capacity (qe,cal) and the rate constant(k2). The results

The experimental data showed a good compliance with the pseudo second-order equation and the correlation coefficients for the linear plots were higher than 0.99 for all the experimental data. These results suggested that the experimental data for the adsorption kinetics of chalcone dye on silk were fitted by the pseudo second-order kinetic model.

\section{REFERENCE}

[1] Emrah, A.E., Ali, U., Halil, K., 2007. Decolorization of synthetic dyes by white rot fungi, involving laccase enzyme in the process. Process Biochem. 42, 1429-1435.

[2] Bhuyan, R., Saikia, C.N., Das, K.K., 2004. Extraction and identification of colour components from the bark of Mimusops elengi and Terminalia arjuna and evaluation of their dyeing characteristics on wool. Indian J. Fibre Text. Res. 29, 470-476.

[3] Shaukat, A., Tanveer, H., Rakhshanda, N., 2009. Optimization of alkaline extraction of natural dye from Henna leaves and its dyeing on cotton by exhaust method. J. Cleaner Prod. 17, 61-66.

[4] Dhar, D.N., 1981. The Chemistry of Chalcones and Related Compounds. A Wiley-Interscience Publication, New York

[5] Bechtold, T., Mussak, R., 2009b. Handbook of Natural Colorants. John Wiley \& Sons, United Kingdom, pp. 268-269.

[6] Shen, P.S., 2009. A simulation study for a class of central composite designs with nested subexperiment. Computational Statistics 24, 481-495.

[7] Navid Nasirizadeh, Hamed Dehghanizadeh, M. Esmail Yazdanshenas, Masoud Rohani Moghadam, Ali Karimia. 2012.Optimization of wool dyeing with rutin as natural dye by central composite design method. Industrial Crops and Products 40 : 361- 366

[8] Weili, J., Zengwei, Y., Jun, B., Li, S., 2010. Conserving water by optimizing production chedules in the dyeing industry. Journal of Cleaner Production 18, 1696-1702 7.

[9] Keka Sinh, Papita Das Saha, Siddhartha Datta .2012.Extraction of natural dye from petals of Flame of forest (Butea monosperma)flower: Process optimization using response surface methodology (RSM). Dyes and Pigments 94 : 212-216 